\title{
Adapting to Climate Change in the Southwest Yukon: Locally Identified Research and Monitoring Needs to Support Decision Making on Sustainable Forest Management
}

\author{
A.E. OGDEN ${ }^{1,2}$ and J.L. INNES
}

(Received 2 January 2008; accepted in revised form 11 December 2008)

\begin{abstract}
In a community-directed forest management context, research is needed that will help both the managers of forest resources and the community residents who set forest management directions to consider climate change in their decision making. Specific research needed in light of climate change to support implementation of the forest management plan for the Champagne and Aishihik Traditional Territory, southwest Yukon, was identified through 1) sessions with local forest practitioners and 2) a community climate change workshop. Local residents highlighted the importance of formalizing a monitoring network based on local knowledge as part of a broader adaptive management framework. They also wanted an important role in any discussion on adapting existing forest management plans, practices, and policies to incorporate climate change considerations. Forest practitioners expressed a need for research to identify forest management tactics that would enable them to achieve community-directed forest management objectives in light of climate change. Addressing these research needs will have benefits beyond just adapting forest management to climate change. Climate change is providing the impetus and a forum for discussing a broader issue: the need for a more comprehensive research and monitoring program to support the sustainable management of forest resources.
\end{abstract}

Key words: climate change, impacts, adaptation, sustainable forest management, southwest Yukon, spruce bark beetle, Yukon Territory, Champagne and Aishihik Traditional Territory, research needs, monitoring

RÉSUMÉ. Dans le contexte de l'aménagement forestier communautaire, il y a lieu de faire des travaux de recherche pour aider les gestionnaires des ressources forestières et les habitants des collectivités qui donnent le ton à l'aménagement forestier à tenir compte du changement climatique lorsqu'ils prennent des décisions. La nécessité de faire des recherches spécifiques à la lumière du changement climatique dans le but d'appuyer la mise en œuvre du plan d'aménagement forestier du territoire traditionnel des Premières nations de Champagne et d'Aishihik, dans le sud-ouest du Yukon, est ressortie : 1) de séances avec des spécialistes en aménagement forestier de la région et 2) d'un atelier communautaire sur le changement climatique. Les habitants de la région ont fait remarquer l'importance d'officialiser un réseau de surveillance s'appuyant sur les connaissances locales dans un cadre plus large de gestion adaptative. Ils désirent également jouer un rôle important dans toute discussion sur l'adaptation des pratiques, des politiques et des plans actuels d'aménagement forestier pour tenir compte des considérations en matière de changement climatique. Les spécialistes de l'aménagement forestier ont également mentionné que la recherche doit déterminer les tactiques d'aménagement forestier qui leur permettraient d'atteindre des objectifs d'aménagement forestier communautaire à la lumière du changement climatique. Le fait de s'acquitter de ces besoins en recherche aura des incidences qui iront au-delà de l'adaptation de l'aménagement forestier au changement climatique. Le changement climatique fournit en fait l'élan et la tribune nécessaires à la discussion d'un enjeu de plus grande envergure, soit la nécessité de se doter d'un programme de recherche et de surveillance plus complet pour appuyer la gestion durable des ressources forestières.

Mots clés : changement climatique, impacts, adaptation, aménagement forestier durable, sud-ouest du Yukon, scolyte de l'écorce, territoire du Yukon, territoire traditionnel des Premières nations de Champagne et d'Aishihik, besoins en recherche, surveillance

Traduit pour la revue Arctic par Nicole Giguère.

\section{INTRODUCTION}

There is now clear evidence that climate change is occurring in regions where forest-based communities and forest ecosystems are vulnerable (Juday et al., 2004; IPCC, 2007).
Even the most aggressive measures to control greenhouse gas emissions will not prevent continued warming (IPCC, 2007). Recent studies documenting research needs associated with climate change have identified the need to expand both observational and experimental work on ecosystem

\footnotetext{
${ }^{1}$ Sustainable Forest Management Laboratory, Department of Forest Resources Management, Faculty of Forestry, University of

British Columbia, Canada; aogden@northwestel.net or aynslie.ogden@gov.yk.ca

${ }^{2}$ Forest Management Branch, Department of Energy, Mines and Resources, Government of Yukon, Box 2703, Whitehorse, Yukon Y1A 2C6, Canada

(C) The Arctic Institute of North America
} 
processes and regional and larger-scale observational, monitoring, and modeling studies (Morgan et al., 2001; ACIA, 2004; C-CIARN North, 2004a, b, c; Mallory et al., 2006; IPCC, 2007). These new data sets and models will increase our ability to forecast ecosystem change and identify vulnerabilities and help us to identify appropriate adaptation options (Clark et al., 2001; IPCC, 2007). However, while research can make valuable contributions to reducing uncertainties, uncertainty is not likely to be reduced dramatically in the next few decades (e.g., Morgan and Keith, 1995; Schneider, 2003). This "deep uncertainty" originates from a variety of factors, including a lack of information, disagreement about what is known or even knowable, long time scales, complexity of the climate system, measurement error, and problems associated with subjective judgments (Moss and Schneider, 2000; Schneider, 2003; Kandlikar et al., 2005). Substantial investments in research will therefore be required if the uncertainties associated with climate change are to be reduced significantly. However, such needs occur within the context of limited resources for research and declining resources for monitoring. Research that targets questions that forest managers need answered to incorporate climate change considerations more effectively into their decision making is likely to have the greatest benefitcost ratio.

Forest practitioners play a key role in the planning and management of forest-based resources. Practitioners are responsible for developing management strategies to meet objectives established through multi-stakeholder forest management planning processes (Williamson et al., 2005). Practitioners work at the interface of local, scientific, and government knowledge and priorities; in the Canadian North, they are most likely to be employed by territorial or First Nation governments or by non-governmental organizations that drive forestry decision making. Northern forest practitioners may possess social, cultural, economic, or environmental expertise and may be holders of local, traditional, or scientific knowledge of forest-based resources, or have some combination of these traits (Ogden and Innes, 2007). While practitioners often have limited time to locate and review research results - these challenges are well known to those who work at the interface between science and policy (e.g., Gamborg et al., 2004; IUFRO, 2007) -it is important to engage them in setting a research agenda because of the interacting climatic and societal influences on ecosystems (Clark et al., 2001). In addition, forest management recommendations arising from research will be more successful if local practitioners help to identify and develop them. Such recommendations are more likely to be consistent with local priorities, norms, and institutions and mainstreamed within regional forest management goals and objectives (Newton et al., 2005; Chapin et al., 2006; Ogden and Innes, 2007).

Recent developments in natural resource management in Canada's North have generated important considerations for research programs targeted to support decision-making. These considerations include 1) changes in the governance of lands and resources resulting from settled land claims and self-government agreements; 2) increased awareness of the value of local and traditional knowledge; and 3) increased desire for local involvement in research activities. First, the distinct differences in the new governance regimes highlight the limited prospects for importing ideas from elsewhere about research needs to support decision making on resource management. In addition, new governance regimes create a need to develop stronger relationships and enhance information sharing between community residents, government agencies, and academics (e.g., Berkes and Jolly, 2002; Wortley, 2003; Clarke and Slocombe, 2004). Therefore, any process to identify research needs that involves developing understanding among these groups is likely to be beneficial. Second, recent efforts to document local and traditional knowledge on changing local and regional conditions are providing extremely valuable insights into vulnerabilities to those changing conditions (e.g., Reidlinger and Berkes, 2001; Berkes and Jolly, 2002; Ford et al., 2006; Gearheard et al., 2006). Awareness of the value of these knowledge systems for identifying and assessing climate change impacts and vulnerabilities for forest-based communities is also increasing (Williamson et al., 2007; Keskitalo, 2004; Kloprogge and van der Sluijs, 2006). Consequently, any process to identify research needs would benefit from drawing on this diverse knowledge base. Finally, research that generates management-oriented recommendations but does not involve local residents, especially in a northern context, is far less likely to be accepted or adopted (Newton et al., 2005). This is particularly true because resource management decisions based on research and monitoring results can significantly affect local communities. Local residents should therefore play an important role in all stages of the research process, including the identification of knowledge gaps, documentation of changes, identification of vulnerabilities, and discussion of the implications of research results for local management decisions (RMTWG, 2005). Several recent examples show the progress that has been made in engaging northern residents in defining research activities (e.g., IPY, 2005; Mallory et al., 2006).

The scale at which uncertainties and knowledge gaps are identified is critical to the identification of research needs that support policy development and decision making. In a recent study, forest practitioners in the Yukon and Northwest Territories highlighted several areas where additional information on climate change impacts would have a significant influence on their decisions (Ogden and Innes, 2007). However, the same practitioners also expressed difficulties in assessing adaptation options and research needs outside a specific geographical context, such as a forest management planning unit, where regionally defined objectives and values for forest management have already been identified. A forest management planning area therefore seems an appropriate scale for identifying research needs associated with decision making (Ogden and Innes, 2007).

Unfortunately, those who are responsible for developing management strategies and those affected by research- 


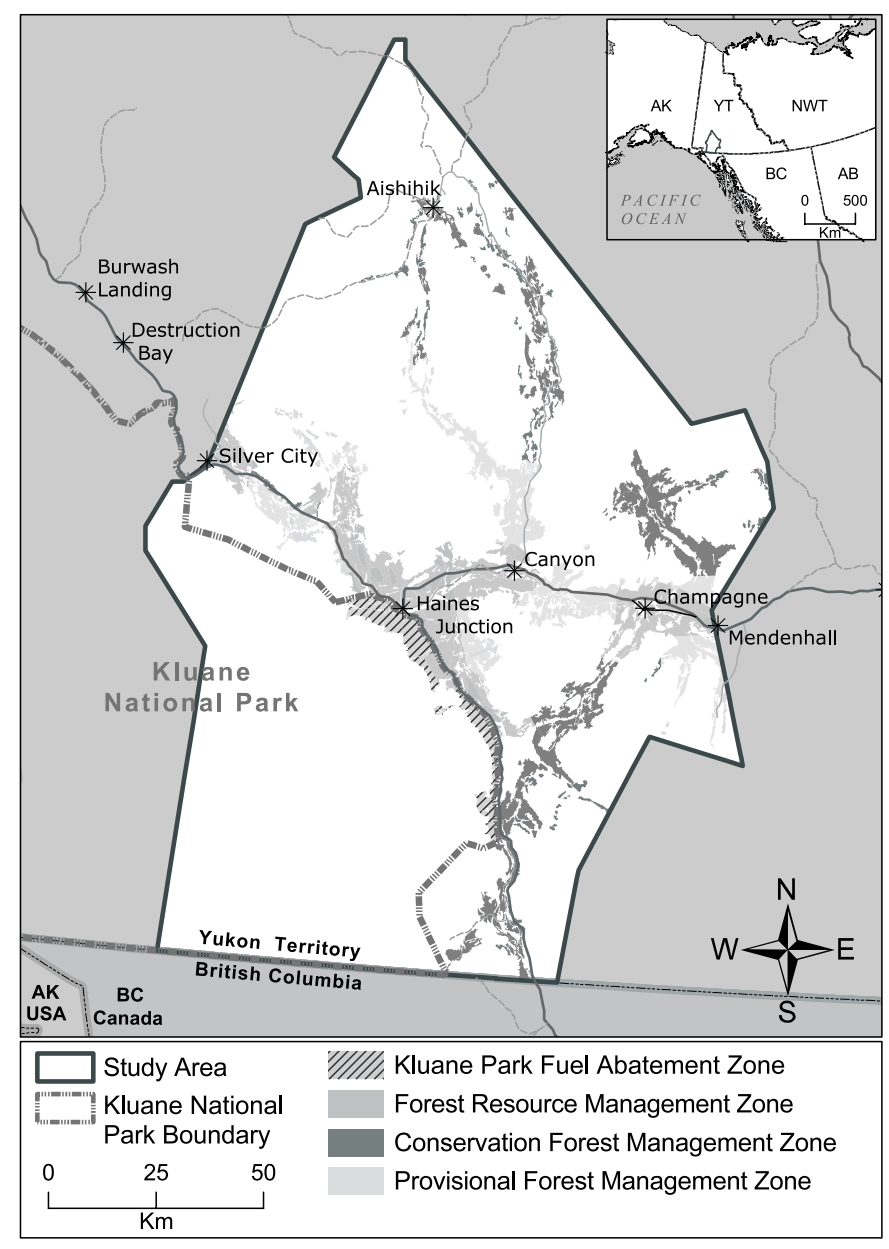

FIG. 1. Map of the Champagne and Aishihik First Nations Traditional Territory in southwest Yukon, Canada (Source: Government of Yukon).

based forest management decisions are rarely involved in setting the research agenda. The development of a community-based forest management research program to support decision making for adaptation is likely to benefit greatly from the engagement of both the practitioners who are responsible for developing management strategies and the community members who set the forest management directions in identifying research needs. This paper describes the research needs identified by local forest practitioners and local residents to incorporate climate change considerations into the implementation of the Strategic Forest Management Plan (ARRC, 2004) for the Champagne and Aishihik Traditional Territory in southwest Yukon. The intent is to identify research needs, not to prioritize them.

\section{STUDY AREA}

The study area encompassed the Champagne and Aishihik First Nations Traditional Territory (CATT) in the southwestern Yukon, Canada (Fig. 1). Over the past 15 years, this region has been experiencing early signs of climate change, notably warmer winters and warmer and drier summers. These changing conditions have contributed to a severe outbreak of the spruce beetle (Dendroctonus rufipennis Kirby) affecting almost two-thirds of a white spruce (Picea glauca) forest in the region estimated at 600000 ha (ACIA, 2004; Garbutt, 2005; Garbutt et al., 2007; Ogden, 2007). This is the largest and most intense outbreak of spruce beetle ever to affect Canada (ACIA, 2004). While climate has played a critical role in increasing the population of beetles to epidemic levels and weakening the defenses of the spruce trees, the extensive forests of mature white spruce characteristic of this region have exacerbated the infestation.

This spruce beetle outbreak has been driving regional forest management and planning efforts since the mid1990s. In December 2004, a Strategic Forest Management Plan (SFMP) was recommended by the locally based Alsek Renewable Resource Council and jointly approved by the Champagne and Aishihik First Nations Government, and the Government of Yukon (ARRC, 2004). The plan outlines community-directed goals and objectives for forest management and identifies reducing fire hazard, promoting forest renewal, providing for economic activity, and preserving wildlife habitat as management priorities. In April 2006, the Champagne and Aishihik First Nations and the Government of Yukon jointly set a harvest level of up to one million cubic meters of beetle-affected timber over 10 years. In February 2007, the two governments also established land management zones where future fuel abatement and salvage harvesting activities would be permitted (Fig. 1: Forest Resource Management Zone) along with areas where conservation is the priority (Fig. 1: Conservation Forest Management Zone) and areas where decisions on forest management priorities are deferred for future decisionmaking (Fig. 1: Provisional Forest Management Zone).

The SFMP commits to an adaptive management framework that includes monitoring the effects of forest management activities and modifying practices as necessary. A local interagency Research and Monitoring Technical Working Group was established to implement the adaptive management framework of the SFMP and to identify research and monitoring priorities. There is a long history of research and monitoring in the southwest Yukon, and an even longer history of firsthand observations of climate and environmental variability. For generations, the people of the Champagne and Aishihik First Nations have made firsthand observations of climate and environmental conditions. Together, traditional local knowledge and scientific knowledge can help us develop an understanding of climate change in this region. However, climate and other forces of change may be creating conditions outside the realm of experience in either knowledge system.

\section{METHODS}

A series of sessions involving local forest practitioners and a community climate change workshop were held to identify the appropriate research needs. Because of differences between the two target groups (e.g., in level of 
scientific knowledge, level of local knowledge, level of operational forestry experience, nature of employment, etc.), different methods were used with each. The experience and expertise of forest practitioners enabled a very structured approach using technical questions and language. For local residents, a community workshop was held that incorporated more opportunities for presentations and discussion and used less technical language. The community workshop took place before the practitioner sessions, and the workshop report was made available to all practitioners upon request. Some of the practitioners attended the community workshop but did not contribute ideas during the community roundtable discussions.

\section{Community Workshop}

A climate change workshop, hosted by the Champagne and Aishihik First Nations and the Alsek Renewable Resource Council, was held in Haines Junction in March 2006. One day was devoted to discussions on the topic "Our Changing Boreal Forest." The more than 130 participants included representatives of government agencies and local residents: more than 100 resided in the region. The workshop included a number of presentations by government scientists, local residents, government practitioners, and Elders. Local residents discussed their observations and provided information on knowledge gaps and research needs through a series of roundtable discussions, one or two for each of the 10 communities in the traditional territory and one for Elders. Each roundtable had a facilitator and a notetaker. Discussions were structured around the following topics:

1. Climate change observations: What changes have you noticed in our weather, environment, forest, fish and wildlife, landscapes, glaciers, and people?

2. Climate change and forest renewal: How might climate change affect the growth of plants and trees? How should we consider climate change in reforestation programs?

3. Climate change and fire management: What are your interests and concerns about fuel abatement activities, including logging, around your community? What fuel reduction options do you feel are best suited for the hazardous areas outside of your community? How would fire affect different traditional uses of forests in the traditional territory? How should we consider changing fire regimes in our management of forests and forest fires?

4. Climate change and fish and wildlife management: Which fish and wildlife species are likely to be sensitive to climate change? What can we do to maintain fish and wildlife in a changing climate? How should we adapt to climate-induced changes in fish and wildlife? How should we monitor these changes and how can local people be involved?

Detailed information on the results of the roundtable discussions, as well as summaries of the presentations, can be found in the workshop proceedings (McKinnon, 2006). These workshop proceedings are cited extensively here with permission from Champagne and Aishihik First Nations Government. The proceedings were analyzed in three ways to identify research needs: 1) we noted research and monitoring needs that workshop participants expressed directly, drawing on their local knowledge and experiences, in response to the questions discussed during the roundtable sessions; 2) we inferred research needs from local observations of climate and environmental change that were either unexpected or unprecedented; and 3) we also noted observations shared in the workshop that presented opportunities for additional research because they were either not documented previously or contrary to what was previously documented.

\section{Forest Practitioner Sessions}

In February 2007, 30 forest practitioners involved in some way with the implementation of the CATT SFMP (50\% of the identified target group) participated in a study that explored their perceptions on climate change adaptation. The majority of participants $(53 \%)$ were employed by territorial government agencies, $20 \%$ by the federal government, $13 \%$ by the First Nations government, and $10 \%$ by non-governmental organizations.

A team was established to guide the planning and implementation of the practitioner sessions. It consisted of researchers from the University of British Columbia and representatives of the Lands and Resources Department of the Champagne and Aishihik First Nations and the Forest Management Branch, Government of Yukon. The team reviewed, revised, and approved the project proposal, identified participants, helped secure funding, and participated in a pilot session. In addition, we consulted a local interagency Research and Monitoring Technical Working Group that is forestry-oriented throughout the research planning process.

Five one-day data collection sessions were held, each with five to eight practitioners. These sessions were moderated by an experienced facilitator, who introduced the goals and objectives of the study and provided necessary background information to assist participants in completing their workbooks. Each participant completed a 65-page workbook of questions designed to gather their informed judgments on climate change impacts and vulnerabilities in the region. Practitioners also assessed alternative adaptation options for their importance to meeting regional management objectives in light of climate change. The workbook concluded with the following open-ended questions, which were designed to elicit perspectives on research needs:

1. The development of a targeted research program involves identifying key uncertainties and knowledge gaps. Can you identify any key uncertainties or knowledge gaps that, if explored, would help forest managers incorporate climate change considerations into forest management 
and planning in the CATT to achieve SFMP goals and objectives?

2. The SFMP incorporates an adaptive management framework. To support adaptive management, the SFMP has specified a number of indicators that are to be tracked to test progress towards forest management goals and objectives. From this exercise, do you believe any different indicators related to forest renewal need to be monitored other than those specified in the SFMP?

Additional details on the results of the practitioner sessions are available (Ogden and Innes, 2009).

\section{PERSPECTIVES OF LOCAL RESIDENTS}

The roundtable discussions that took place at the community workshop "Climate Change in Our Backyard" (McKinnon, 2006) generated a wide variety of research and monitoring needs related to climate and environmental change and supporting adaptation to these changes (Tables 1 and 2). The following quotations from workshop participants were recorded in McKinnon (2006). The individuals quoted are not identified to protect participant confidentiality.

\section{Local Observations}

The local observations of climate and environmental change shared at the workshop fell into one of three categories: 1) they are complementary to the results of scientific literature or previous efforts to document local observations; 2) they do not appear in published, scientific literature or are previously unknown or unobserved by local residents; or 3) they are contrary to what is published in some scientific reports or what locals have observed in the past, or both. The latter two categories present opportunities for additional research to document observations in greater detail and to explore the reasons behind unexpected observations.

The most common changes in weather observed by local residents included less snow, more variable weather and temperatures, more rain (as opposed to snow) in winter, warmer winters, more wind, more weather events, and overall drier conditions. Several said that First Nations ways of predicting the weather, using indicators such as sky color, leaf condition, and moonlight, no longer work or are not as effective.

Workshop participants also shared observations of how forest vegetation has been changing in recent years. Changes in phenology (e.g., "budding during winter warm spells"), species abundance (e.g., "new blue and yellow flowers" and "new black vegetation on the forest floor"), species distribution (e.g., "the tree line and other plants, like dandelions, are moving higher on the mountains") and forest health (e.g., "trees are getting smaller"; "lichen and mosses are dying out"; "little green worms [are] killing willow leaves"; "a new fungus on cottonwood trees"; and "a new mold growth on trees") along with ecosystem changes (e.g., "wetlands and lakes are turning into meadows"; "existing meadows are drying out"; lakes — specifically Dezadeashare "filling in with weeds" and changes in non-timber forest products (e.g., "berries much smaller and drier") have been observed in the region.

There were also many observations of changes in fish and wildlife populations, including sightings of new species (e.g., cougar, hummingbirds, a new "red bird," woodrat). Some populations were noted to be increasing (e.g., bears, wolves, otters, bats, woodpeckers, "more southern birds like cowbirds and blackbirds," swallows), and others to be decreasing (e.g., moose, caribou, gophers, "fewer fish overall and fewer spawners in particular"). Concerns were shared over the impacts of increasing populations of introduced wildlife species (e.g., bison, elk) in the area. The snowshoe hare, a species whose population normally fluctuates in cycles, "does not appear to be recovering from low points as quickly as in the past," while other species whose populations were down (e.g., porcupines and wolverine) are now seen to be improving. Poorer fur quality amongst all fur-bearing species was noted. Waterfowl migration has been changing, with "birds returning sooner, leaving sooner, and taking different routes." Some observed that fewer birds are overwintering (e.g., chickadees and juncos).

\section{Adaptation Decision Making}

Workshop participants raised a number of concerns about perceived values-at-risk and issues that pertain to forest management in a changing climate. The general theme in managing forests for climate change was to "take a cautious approach," one that is informed by local knowledge, local monitoring, targeted research, enhanced communication, and extensive local consultation, and to "be careful with what we have."

The question of what should be planted (or whether planting should happen) in harvested areas was raised by many of the local residents. Some felt that a better understanding of future conditions is needed before replanting occurs because "we don't want to replant today with trees that won't survive if conditions change." Participants also advised replanting with economically beneficial species. Some were against planting more spruce, while others suggested that spruce and poplar were good choices for replanting as they are both medicinal trees. Another option suggested was to reforest with species that have already been successfully planted in the region. A few participants cautioned that the uses of harvested trees "should be diverse" and that tree harvesting should be "done carefully because tree growth in the region is slow."

Although new species were suggested for replanting, including birch, tamarack, and lodgepole pine, many participants advised proceeding very cautiously with their use. One commented that local people did not expect lodgepole pine to survive in their area. Some strongly opposed planting with new species, while others thought it was an interesting question that could be tested and monitored before 
TABLE 1. Summary of research needs identified through forest practitioner sessions and a community climate change workshop to support the incorporation of climate change considerations into the implementation of the Strategic Forest Management Plan (ARRC, 2004) in the Champagne and Aishihik Traditional Territory, southwest Yukon.

Functioning forest ecosystems (ARRC, 2004:24):

- How will forest ecosystems in the CATT respond to climate change?

- What are the implications of changes in phenology, sightings of new understory vegetation, changes in species distribution, and ecosystem changes for forest ecosystem function?

- What are the implications of forest health concerns? Are forest health concerns increasing in magnitude, intensity, or severity above what has been seen in the past? If so, why?

- What are the impacts of increasing populations of introduced wildlife species (e.g., bison, elk) on forest ecosystem function?

Community wildfire risk and hazard abatement (ARRC, 2004:34):

- What is the level of mortality of white spruce in spruce beetle-affected stands in the region? What is the impact of mortality on the relationship between beetles, fuel, and fire hazards?

- How effective are alternative community and interface zone fuel treatments in reducing fire intensity to a level at which direct fire suppression tactics could be used?

- What are some more reliable future scenarios for winter and summer precipitation, drought index, fire and insect disturbance, and growing season length in light of climate change? How might these scenarios influence choices regarding how to carry out community fire hazard abatement?

- How effective are alternative fuel abatement techniques (salvage harvesting, selective logging, prescribed burn, encouraging deciduous tree growth) in reducing fire-related threats to community-identified values-at-risk?

- What is the effect of spruce beetle-killed forests and climate change projections on fire hazard?

- What is the impact of fire on hunting and trapping, berry picking, traditional medicine harvesting, firewood availability, recreation and tourism, and personal loss? How might these impacts influence how and where to carry out fire hazard abatement?

Assess the feasibility of silviculture treatments and enhance knowledge with regard to selecting tree species for the region (ARRC, 2004:39):

- What are some more reliable future scenarios for winter and summer precipitation, drought index, disturbance regimes, and growing season length in light of climate change? How might these scenarios influence choices regarding what tree species to regenerate? Can thresholds in climate conditions be defined regarding the establishment and growth of tree species?

- How long does it take to establish an adequate number of young trees through natural forest regeneration on harvest blocks in the CATT?

- What are the characteristics of the natural regeneration in spruce-beetle affected forests? Has there been a significant release in growth in the understory spruce? How might climate change affect natural regeneration in spruce beetleaffected stands?

- What influence does alternative site preparation techniques or harvesting methods have on regeneration success?

- What is the genetic variability among spruce trees in the region with respect to tolerance to climate, pests, and pathogens?

- Is there an increased regeneration lag in areas harvested in winter and left to regenerate naturally?

- What effect does exposing mineral soil have on the success of natural regeneration?

- How do the growth and survival of local spruce compare to those of spruce from different latitudes and altitudes and commercial species other than spruce?

- Can genotypes resistant to drought, insects, and disease be identified within the local spruce population?

- How effective is prescribed burning as a tool to promote forest renewal? What sites are most likely to benefit from a prescribed burn?

- What should be planted in harvested areas (or should planting happen there)?

- Which trees will and won't survive (including medicinal trees such as spruce and poplar; new species such as birch, tamarack and lodgepole pine; and economically beneficial trees) if climate conditions change?

- Will climate change result in impacts on plant and tree growth such as reduced growth, death of some trees, reduced reproductive success, loss of some species, and new species moving in?

Protect fish and wildlife populations and their habitats (ARRC, 2004:27):

- How has the spruce bark beetle infestation changed patterns of wildlife use in these forests? Have populations shifted or expanded their ranges, or has seasonal use of certain areas changed? How are wildlife populations, ranges, and habitats expected to respond to climate change?

- How can climate change considerations be incorporated into the identification of critical habitats for species-at-risk and other high wildlife value areas? What is the projected future status of these areas in this region in light of climate change?

- What are the most important wildlife populations, wildlife habitats, and breeding areas to protect from possible negative impacts of forestry development? How effective are the strategies that we have in place for protection of these populations and habitats?

- Where are unique, rare, threatened, or endangered plants and medicinal plants found in the region? What forest management practices should be implemented to ensure their conservation?

- What are some alternative approaches to wildlife habitat management (e.g., prescribed burning to create desired earlysuccessional habitat for moose)? What is the potential for some of these approaches to be applied in the southwest Yukon? 
TABLE 1. Summary of research needs identified through forest practitioner sessions and a community climate change workshop to support the incorporation of climate change considerations into the implementation of the Strategic Forest Management Plan (ARRC, 2004) in the Champagne and Aishihik Traditional Territory, southwest Yukon - continued:

\begin{tabular}{|c|c|c|}
\hline \multirow[b]{2}{*}{ Research Needs and Questions } & \multicolumn{2}{|c|}{ Identified by Local } \\
\hline & $\begin{array}{c}\text { Forest } \\
\text { Practitioners }\end{array}$ & Residents \\
\hline \multicolumn{3}{|l|}{ Protect fish and wildlife populations and their habitats (ARRC, 2004:27) continued: } \\
\hline - How can retention areas in harvest blocks be designed to be more likely to withstand windthrow? & • & \\
\hline $\begin{array}{l}\text { - What are the cumulative effects of forestry activities in the Champagne and Aishihik Traditional Territory and climate } \\
\text { change on the ecological integrity of the adjacent Kluane National Park and Reserve? }\end{array}$ & • & \\
\hline -What are the implications of newly sighted species to local wildlife populations and their habitats? & & • \\
\hline \multicolumn{3}{|l|}{$\begin{array}{l}\text { Ensure appropriate wildlife movement corridors between important habitats and key landscape features (ARRC, } \\
\text { 2004:25): }\end{array}$} \\
\hline $\begin{array}{l}\text { - What are the most important wildlife movement corridors to protect from possible negative impacts of forestry } \\
\text { development? What is the projected future status of these areas in this region in light of climate change? }\end{array}$ & • & \\
\hline $\begin{array}{l}\text { - How can climate change considerations be incorporated into coarse-scale biodiversity management practices, such as } \\
\text { wildlife corridors and landscape connectivity? }\end{array}$ & • & \\
\hline \multicolumn{3}{|l|}{ Implement an adaptive management strategy (ARRC, 2004:26): } \\
\hline - What are important ecological benchmarks in the region? & • & \\
\hline -What degree of actual or anticipated climate change would necessitate a change in forest management practices? & - & \\
\hline $\begin{array}{l}\text { - What influence might climate change have on tradeoffs between social, economic, and environmental objectives of } \\
\text { forest management in the region? }\end{array}$ & • & \\
\hline $\begin{array}{l}\text { - What is the capacity of existing institutions and public bodies to adapt to a rapidly changing environment? How can } \\
\text { this capacity be enhanced? }\end{array}$ & $\cdot$ & \\
\hline \multicolumn{3}{|l|}{ Maintain forest productivity in areas subject to harvest practices (ARRC, 2004:25): } \\
\hline $\begin{array}{l}\text { - How are permafrost regimes changing in the region? What present or future effects will these changes have on the } \\
\text { stability of forest roads and cutblocks? How should operational practices adapt to changing permafrost regimes to } \\
\text { minimize the impacts of roads and harvest blocks on soil resources? }\end{array}$ & • & \\
\hline $\begin{array}{l}\text { - How are precipitation regimes changing in the region? What effect is this change having on the erosion potential of } \\
\text { soils, particularly the fine-grained loess soils that are prevalent in the region? How should operational practices adapt } \\
\text { to changing precipitation regimes to minimize the impacts of roads and harvest blocks on soil resources? }\end{array}$ & • & \\
\hline \multicolumn{3}{|l|}{ Enable and encourage forest-based activities that stimulate employment opportunities (ARRC, 2004:27): } \\
\hline - What are the needs of the community regarding desired lifestyle and employment? & • & \\
\hline - What is the demand for wood products from beetle-salvaged wood? & $\bullet$ & \\
\hline \multicolumn{3}{|l|}{ Coordinate financial and human resources (ARRC, 2004:30): } \\
\hline $\begin{array}{l}\text { - What are the true costs of salvage harvesting in the CATT (including government consultation, inventory, and } \\
\text { planning efforts)? }\end{array}$ & • & \\
\hline \multicolumn{3}{|l|}{ Provide for a sustainable domestic harvest of wood, meat, fish, berries and other forest products (ARRC, 2004:28): } \\
\hline $\begin{array}{l}\text { - How has the spruce beetle infestation changed traditional uses of the land by the Champagne and Aishihik First } \\
\text { Nations people? }\end{array}$ & • & \\
\hline
\end{tabular}

going forward with full replanting. Some residents liked the idea of replanting with "bigger, lusher vegetation," but others strongly preferred natural regeneration to planting as they felt the natural succession of the forest should be allowed to continue alongside climate change. Another argued that "our white spruce forest is rare and special, so we should not plant species not native to the region." For forest renewal, many indicated that the first step should be observation. Some indicated they expect climate change to result in impacts on plant and tree growth such as reduced growth, death of some trees, reduced reproductive success, loss of some species, and new species moving in. Participants noted that a better sense of temperature changes, the effects of increased ultraviolet rays on seedlings and buds, and soil and climate conditions is needed before reforesting in areas affected by the spruce beetle. We feel that these are all areas where monitoring could be targeted to track the changing forested landscape.
Participants also discussed climate change and fire management. The degree to which forests killed by the spruce beetle and future climate change scenarios increase fire hazard was noted by some as areas for further research. Some residents considered that research was needed to explore the effectiveness of alternative fuel reduction techniques in reducing fire-related threats to values-atrisk identified by communities. Traditional uses noted as most likely to be affected by fire were hunting and trapping, berry picking, traditional medicine harvesting, firewood availability, and recreation and tourism. Residents suggested many ways to reduce fire risk, including "FireSmart" programs, reducing fuels around residential developments, selective logging to protect private property, encouraging deciduous tree growth, and prescribed burning. Prescribed burning was a new fuel abatement idea for many. Several indicated they consider it to be a good tool to prevent uncontrolled wildfire, while others expressed 
TABLE 2. Summary of monitoring needs that were identified through forest practitioner sessions and a community climate change workshop to support the incorporation of climate change considerations into the implementation of the Strategic Forest Management Plan (ARRC, 2004) in the Champagne and Aishihik Traditional Territory, southwest Yukon.

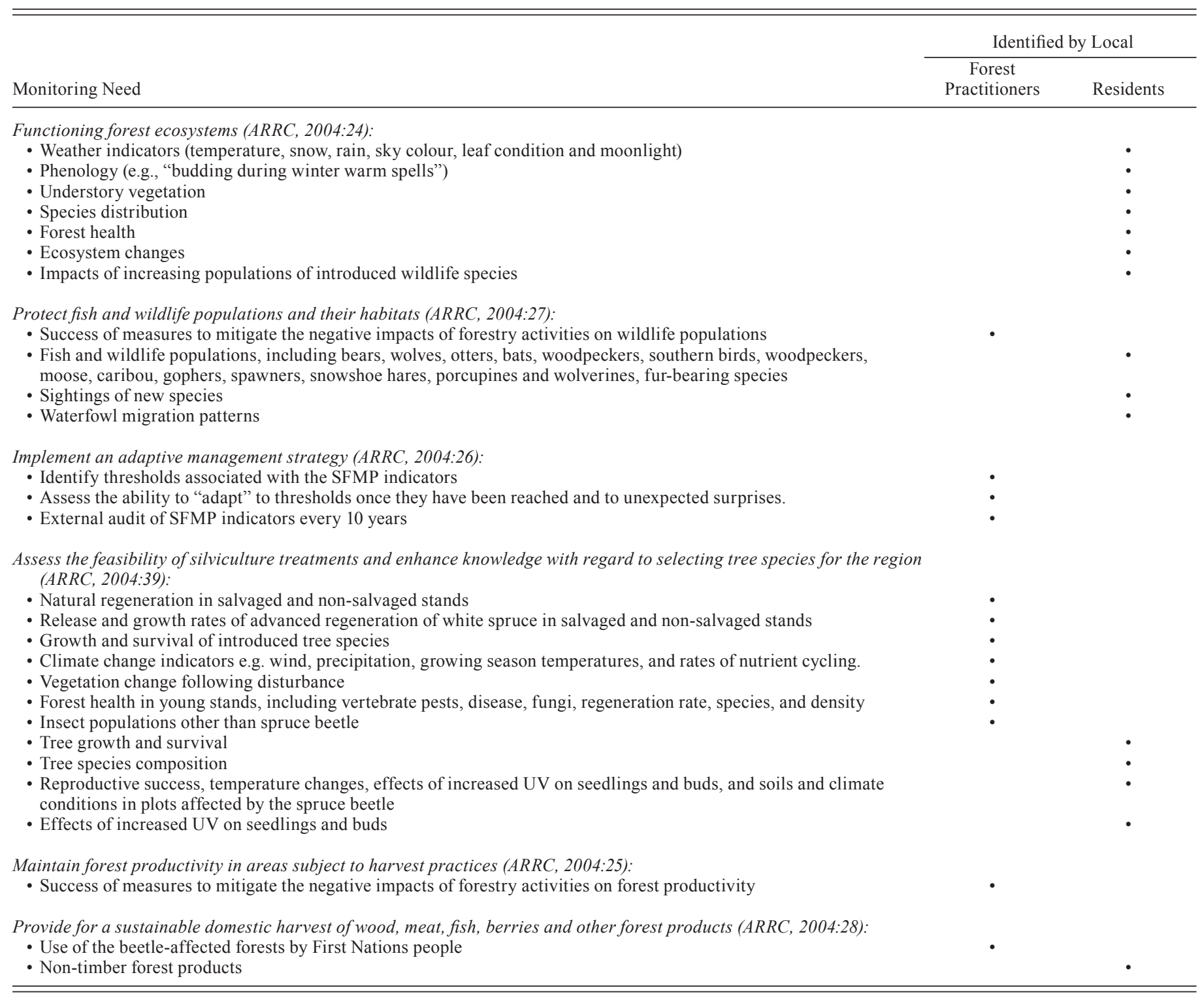

concerns over this technique and felt there should be no controlled burning in the area.

For fish and wildlife management, workshop participants indicated that collaboration, reliance on local input, and careful planning are needed to adapt management strategies in light of current and anticipated climate change. Some participants expressed optimism that animals are quite adaptable and resilient, while others thought that northern species, animals that hibernate, and less mobile species may be more sensitive to change. Some thought that since change is inevitable, it is better for people to just let nature take its course. Many said there must be conservative and sensitive planning with heavy local involvement to ensure local knowledge and values are expressed in any adaptation-oriented planning process. Again, monitoring was noted as an area where local people should be engaged to observe and record change.

\section{PERSPECTIVES OF FOREST PRACTITIONERS}

The needs identified by local forest practitioners fell into five broad categories: 1) biodiversity conservation, 2) climate change impacts, 3) operational trials, 4) forest renewal monitoring, and 5) socio-economic and institutional dimensions of climate change adaptation (Tables 1 and 2).

\section{Biodiversity Conservation}

Practitioners indicated that additional research is needed to support fine-filter (e.g., stand-level) measures to conserve biodiversity in light of climate change. The regional Integrated Landscape Plan identifies High Wildlife Value Areas within the Forest Resource Management Zone. Some practitioners indicated the need to map these high wildlife value 
areas, as well as critical habitat for species-at-risk, to identify the areas more clearly and project the future availability of these habitats. It was noted that protectionist and population control approaches dominate wildlife management in this region, and doubts were expressed over the effectiveness of these approaches for maintaining desired wildlife population levels under different scenarios of climate change. Practitioners indicated that more research is needed on the potential for applying alternative approaches to wildlife habitat management here, such as prescribed burning to create the early successional habitat desirable for moose. Research to locate and map the presence of unique, rare, threatened, or endangered plants (particularly those found only in the region) and medicinal plants was also mentioned as needed to promote the conservation of these species.

Practitioners also indicated that more information is needed on how to incorporate climate change considerations into coarse-filter (e.g., landscape-level) biodiversity management practices, such as wildlife corridors and landscape connectivity. A number of practitioners wanted more information on the patterns of use by wildlife of beetle-affected forests to help them determine whether populations of various wildlife species have shifted, expanded their ranges, or changed their seasonal use of certain areas. A few considered the establishment of new protected areas to be a "no regret" choice that would keep options open for future land use. These new areas were seen by some to reduce the risk that proposed forestry operations in the area would "mess up the system." It was noted that protected areas provide important ecological benchmarks for adaptive management studies, and some suggested that more research to identify ecological benchmarks in the region is needed. Others argued strongly against establishing more protected areas, citing the presence of Kluane National Park and Reserve and the desire expressed by community members that forestry should contribute to regional economic diversification. One practitioner noted that additional research into how climate change may influence tradeoffs between economic and environmental objectives in the regional context would be of interest. It was also recommended that Parks Canada conduct a detailed cumulative effects analysis of the impact of forestry activities and climate change on the ecological integrity of the adjacent Kluane National Park and Reserve.

\section{Understanding Climate Change Impacts}

Improved scenarios of precipitation and soil moisture conditions, practitioners stated, are their first and foremost need. Many noted that this region has shown a trend towards drier summer conditions in recent years even though scenarios project an increase in precipitation. It was noted that warming with more precipitation could improve site productivity, whereas if drying continues to occur, then site productivity may decrease. Precipitation scenarios were considered a critical knowledge gap because choices regarding which tree species to regenerate may be highly influenced by the potential shifts in both winter and summer precipitation.
Practitioners also indicated that regional projections of future fire and insect disturbance regimes would be useful. Many indicated the need for more refined projections of climatic parameters that directly pertain to forestry, such as length of the growing season, drought index, fire weather index, and extreme events. Some indicated that identifying thresholds that would trigger a change in forest management practices would be useful to support decision making.

Some practitioners noted that more detailed information is needed on the success of natural regeneration in forests affected by the spruce beetle, including areas where salvage logging has occurred, and how natural regeneration in the region may be affected by climate change. One noted that the relationship between climate variables and forest successional trajectories needs to be better understood. Completion of a more detailed forest inventory was suggested, along with a study on stand dynamics. A few noted that the development of an ecosystem classification guidebook similar to those available in most other parts of Canada (e.g., Delong, 2004) would be useful to help track and document changes in ecosystems arising from climate change. Practitioners also expressed a need for research into the genetic variability among spruce trees in the region, along with research into spruce physiology as it relates to climate, pests, and other pathogens in the region, and indicated that this type of research needs to take place before importing new species or genotypes or converting stands to other species.

A few practitioners noted that additional research is needed on how climate change affects the management of soil resources, particularly where permafrost is present. The observation that traditional winter harvesting methods do not create sufficient ground disturbance to promote natural regeneration, as shown by the increased regeneration lag in areas harvested in winter and left to regenerate naturally, was shared by a few practitioners. However, other practitioners noted that summer road construction and harvest increase the potential for soil disturbance, particularly in permafrost areas where south-facing slopes could become sources of siltation as the active layer melts in the summer. In addition, several noted that increased precipitation may also increase the erosion potential of soils, particularly the fine-grained loess soils that are prevalent in the region. A few indicated that more research is required on how to balance minimizing the impacts of roads and harvest blocks on soil resources with maximizing the opportunity for natural regeneration, particularly in view of potential changes in permafrost and precipitation regimes.

Many practitioners indicated that uncertainties associated with climate change projections justify the monitoring of a broader range of climate indicators than are currently being tracked and noted the need for an enhanced weather monitoring network in the region and across the Yukon. Currently, nearly all climate stations in the Yukon are located in valley bottoms, with virtually no climate monitoring at higher elevations (e.g., forested areas at mid-slope and ridge tops). Other areas that were noted by practitioners as deserving further research included the impacts of 
climate change on wildlife and wildlife habitat, phenology, hydrology and watershed dynamics, non-timber forest resources, forest soil dynamics, nutrient cycling and decomposition dynamics, stream temperature and aquatic invertebrates, and the forest carbon budget.

\section{Operational Trials}

Practitioners suggested several operational trials needed to put the adaptive management principles they discussed into practice, emphasizing the educational value of such trials. Trials to assess alternative harvesting systems in beetleaffected stands were strongly recommended. In particular, operational trials are needed to assess the level of tree retention appropriate under different site conditions and to aid in the design of retention areas that are more likely to withstand windthrow.

Prescribed burning is of considerable interest to many practitioners, but some thought that the challenges inherent in this activity (e.g., local inexperience, risky fuel conditions, expense, identifying a suitable location, etc.) may preclude trials in the region. Because of the current emphasis on fuel reduction in the SFMP, practitioners suggested undertaking operational trials to test the effectiveness of alternative community and interface zone fuel treatments. A few suggested these might involve either modeling or active experimentation, and one indicated that the results of this research should indicate whether the treatments would be effective in reducing fire intensity to a level at which direct fire suppression tactics could be used.

Many indicated that research on reforestation options (including the option of not planting at all) in harvested areas would be useful to inform decision making. Several indicated that operational trials to assess the performance of local spruce against spruce from different latitudes and altitudes and commercial species other than spruce would be useful. Some thought that more work on seed from surviving beetle-affected trees is needed to assess any genetic factors that may explain why these trees were able to survive the infestation (e.g., better vigour, less attraction, natural resistance, better drought resistance). The development of a seed orchard was noted as being beneficial to future research and reforestation programs.

A few expressed the need to identify management strategies that are likely to perform well across the range of climate-change scenarios. This was considered especially important by some practitioners because of the length of time it takes to generate results from "active" adaptive management studies. Some also acknowledged that the results generated by operational trials would not be available within the timeframe required for current decisions affecting the region's forests.

\section{Forest Renewal Monitoring}

Several practitioners noted the need for monitoring of indicators to improve the understanding of natural regeneration dynamics in managed and unmanaged stands, particularly indicators that will help to monitor the effectiveness of measures to mitigate the cumulative impacts of forestry and climate change on forest productivity and biodiversity. Several people suggested monitoring indicators of tree growth and survival in different types of managed and unmanaged forest in order to facilitate comparisons of 1) regeneration in naturally regenerated stands and planted areas, including areas with introduced tree species, 2) different site preparation techniques, and 3) release and growth rates of advanced regeneration of white spruce in nonsalvaged stands as compared to those in stands that have been salvage-logged. A few noted the need for indicators related to forest renewal that also provide a measure of changes in land use by First Nations people.

Practitioners also expressed the need to monitor indicators of climate change, as decisions on management interventions related to forest renewal may be influenced by the changes in climate that are taking place. Suggested indicators included wind, precipitation, growing season temperatures, fire severity and frequency, and rates of nutrient cycling, some of which are already monitored, but could be monitored more extensively. Practitioners noted the need to monitor indicators of vegetation change following disturbance (e.g., insect, disease, fire, flood, mass wasting, and avalanche). One suggested that a long-term photographic series from permanent sample points to document forest change would be useful. A few suggested monitoring of indicators of health or change in young stands, including vertebrate pests, disease, fungi, regeneration rate, species, and density, as well as more extensive monitoring of spruce beetle and other insect populations that may affect forest health.

A few practitioners expressed the viewpoint that indicators are useful only when monitored within the context of thresholds that can be used to identify when a management response is required. It was suggested that research be carried out to identify these thresholds; however, it was noted by one practitioner that this would be challenging to do. Some practitioners indicated that local residents needed to be involved for the thresholds to be meaningful at the community level. A few noted the need for indicators that measure the ability of institutions to adapt or respond to thresholds once they have been reached. One suggested an external audit of indicators every 10 years to ensure their independence from bias in interpretation.

Many practitioners noted that human resource capacity needs to be increased to support the implementation of SFMP monitoring requirements. The creation of opportunities to involve community residents in monitoring activities was suggested as a way to increase human resource capacity and community involvement in forest management. One noted that an enhanced ability of young people to understand their forest needs to be a legacy of the forest management process, particularly because of the role youth will play in the future in carrying out the forest management plans that are being developed today. A suggestion 
was made to include forest ecology courses in experiential learning programs at school as a means to increase the involvement of local youth.

Finally, it was noted that the SFMP already contains a comprehensive list of indicators. Many felt that some experience should be gained with monitoring this list before it is modified or new indicators are added. Some expressed concern over the current level of capacity to monitor what is outlined in the SFMP.

\section{Socio-economic and Institutional Dimensions}

A few practitioners noted that social sciences could be used more formally to support forest management planning in the region. It was noted that historically, ecological research has been emphasized over socio-economic research. One participant was concerned that the wellintended goals of forest management regarding community sustainability and benefits and ecosystem functioning are being compromised by political actions to support and encourage economic activity. In addition, one practitioner indicated that the needs of the community regarding desired lifestyle/employment have not been objectively studied and are not well known. A few practitioners indicated that research is needed to enhance understanding of indicators in the plan related to quality-of-life measures. In addition, more economic research is needed. Suggestions included an evaluation of the viability of the forest industry in the region; an assessment of the true costs of establishing the forest industry (including government consultation, inventory, and planning efforts); a projection of the potential future use and demand for wood products in the region, in the Yukon, and globally, and of what markets can be accessed economically now and in the future.

Some indicated that research is needed on the capacity of existing institutions and public bodies to adapt to a rapidly changing environment, particularly in the Yukon, where institutional change itself has been extensive in recent years. For example, devolution of resource management responsibilities from the federal government to the territorial government in 2003 and the creation of new comanagement agencies and First Nation governments arising from the settlement of land claims and self-government agreements since the mid 1990s present both challenges and opportunities to adaptation. A few noted that institutions should not increase the vulnerability to change through inflexible policies, indicating that research should be carried out to determine where policy and regulatory changes are needed and to ensure that mitigation and adaptation are possible. Lastly, many practitioners felt that more indicators pertaining to socio-economic aspects of sustainable forest management need to be identified and monitored to ensure the plan is meeting the full range of management objectives and improve understanding of the socio-economic dimensions of climate change.

\section{COMPARISON OF RESEARCH AND MONITORING NEEDS}

While practitioners articulated research needs clearly, the community-based discussions were less direct. Many observations reported during the workshop suggested potential research, but local residents did not always associate an observed change with a research need. The workshop produced a very different set of research monitoring needs, emphasizing the importance of involving local communities in the identification of research priorities. However, several research and monitoring needs were shared by both groups, although they may have been articulated differently. For example, research to inform decisions related to forest renewal and the need to conduct operational trials were emphasized by both groups, as was the need to monitor indicators of climate and environmental change. Some of the research and monitoring needs identified by practitioners were not expressed to the same extent at the community workshop, and vice-versa. Participants at the community workshop placed much more emphasis on addressing research and monitoring needs through community involvement, seeing this as a means both to support greater community participation in the forest management process and to incorporate local knowledge and expertise. The practitioners placed more emphasis on research needs related to identifying forest management tactics and strategies suitable to achieve community-directed goals and objectives. The local residents tended to suggest monitoring needs that were simpler and more oriented towards local observations (e.g., berry counts), whereas the practitioners tended to suggest more equipment-intensive and technical methods (e.g., the use of satellite data). Local observations that were shared during the community workshop may enhance the depth and scope of more structured approaches to monitoring in the future.

\section{RECOMMENDATIONS}

From the results of this study, we offer the following four recommendations:

1. Develop a more comprehensive and targeted research and monitoring program to address the specific needs for information identified by practitioners and residents as essential to support decision making on forest management in the region;

2. Embrace uncertainty in regional forest management decision making by identifying forest management options and strategies that are likely to perform well across a range of future climate conditions;

3. Establish a community-based forest monitoring program as part of a broader adaptive management framework; and

4. Improve the communication of research and monitoring results. 


\section{Research and Monitoring Program}

Several possible explanations exist for the current gaps in research and monitoring activities. To explain these gaps, it is necessary to explore who funds research and monitoring - in northern Canada this is mostly the government (territorial or federal), university-oriented research councils, or foundations - and how these agencies decide what to fund.

The current level of forestry-oriented research and monitoring activities that are either funded or carried out by the Government of Yukon in the region, and across the Yukon, is limited. The Government budget for research and monitoring as a whole is limited, and the small scale of forestry activity across the Yukon means that only a small proportion of this total budget is allocated to forestry. Since the 1990s, federal agencies in the Yukon, including the Meteorological Service of Canada, Canadian Wildlife Service, the Department of Indian and Northern Affairs, the Canadian Forest Service, and Parks Canada, have substantially reduced their monitoring activities. For example, the federal Forest Insect and Disease Survey was cut in 1995; however, even prior to the cutbacks this program was inadequate to detect largescale pest outbreaks - the current spruce beetle outbreak was not noticed until the early 1990s, when over 30000 ha of forest had already been affected. When the management of natural resources was devolved from the federal Department of Indian and Northern Affairs to the Government of Yukon in 2003, responsibilities for forest health monitoring were also transferred. As yet, devolution has not resulted in any improvement in forest health monitoring efforts in the Yukon; however, at the time of writing, this program was under review. Since climate change is anticipated to exacerbate forest pest issues, the Yukon is increasingly vulnerable to large-scale pest outbreaks that may remain undetected until they are too large for preventative measures to be effective.

Governments also support a number of national and international research and monitoring programs, such as the International Polar Year, Arctic Monitoring and Assessment Program, Circumpolar Biodiversity Monitoring Program, Ecological Monitoring and Assessment Network, Northern Ecosystem Initiative, and Canadian Climate Impacts and Adaptation Program. However, these programs often fail to consider how much research and monitoring is needed to support the scale and context at which many natural resource management decisions are made. National and international research and monitoring programs are commonly ineffective in engaging in research priority identification by either those responsible for making decisions at the scale of the management unit or those affected by the management decisions. As a result, research and monitoring are often less relevant than they could be for decision making at the local scale. Governments are starting to recognize this shortcoming. For example, Parks Canada is reviewing its monitoring activities to ensure they are targeted to reporting on indicators of ecological integrity in the national parks, a new focus of park management (Parks Canada, 2000; Timko and Innes, 2009).

In northern Canada, the majority of research is funded by the Natural Sciences and Engineering Research Council (NSERC), the Social Sciences and Humanities Research Council (SSHRC) and the Canadian Foundation for Climate and Atmospheric Sciences (CFCAS). As a result, these agencies play a large role in setting the research agenda for the North. NSERC invested nearly \$25 million in 2006-07 in 234 northern researchers. The majority of the funding was received by researchers in physical science departments in eastern Canadian universities to study northern climate and climate change (NSERC, 2007). As of April 2006 , the CFCAS has invested a total of $\$ 93.8 \mathrm{M}$ in university-based research related to climate and atmospheric sciences, in 19 collaborative networks, 2 major initiatives, and 123 projects (CFCAS, 2006). In 2007, SSHRC announced the allocation of $\$ 700000$ in northern research grants associated with IPY, and the agency has funded $\$ 3.2$ million in northern research through a program to help develop and revitalize Canadian research in and on the North (SSHRC, 2007). Given the levels of funding, greater efforts should be made to communicate to these agencies what research is needed to support decision making for adaptation.

What explains the current gap in the level of funding for research provided by these agencies, and the funds actually needed for decision-targeted research and monitoring? There are a number of potential explanations, including how well these research needs have been articulated in the past, the interest level of either government decision makers or university-based researchers in exploring these topics, challenges in developing the types of relationships between researchers and communities that are required to carry out these projects, and the decision-making process for establishing funding priorities. A Dialogue on Northern Research, held in Whitehorse in 2004, provided an opportunity for northern stakeholders to identify strengths, gaps, and barriers in northern research and ways to improve collaboration between research users and research funders. A commitment was made to organize similar meetings every two or four years to ensure the dialogue continues and progress continues to be made to improve linkages between funders and users of research (NSERC, 2004).

Whether or not the participatory approach reported here is more successful in generating research targeted to support decision making than the current approach employed by governments and research funding agencies can only be assessed over time. Ultimately, the success of research and monitoring to support decision making will depend on whether or not such activities are funded, and whether or not capacity can be developed within local governments and residents to either carry out or meaningfully participate in the studies. Because of the extensive list of research and monitoring needs that were expressed in this study and the long-term implications of forestry activities, a strategic approach to the development of a research and monitoring 
plan is needed. Subsequent work is needed to engage local residents and forest practitioners, scientists, and government representatives in prioritizing the list of research needs generated by this study. The level of investment in research and monitoring activities envisioned by practitioners and residents makes it essential to overcome the barriers currently restricting this type of research. A higher level of active community participation in research and monitoring is needed to ensure that any element of a decision-support research program that is undertaken by outside researchers is supported locally and that local involvement in project planning is effective to ensure results are meaningful to the local context.

\section{Uncertainty in Forest Management}

Practitioners consulted in this study suggested that scenario analyses should report on a number of climate and related indices. Historical summaries and future projections of many of these indicators are not currently available for the Yukon. While bioclimatic profiles are available for some point locations in Canada, including four locations in the Yukon (which include scenarios of heating and cooling degree days, growing degree days, water surplus and deficit, and frequency of precipitation), these profiles fall short of providing the range of information needed to support adaptation decision making in a forest management context (CCIS, 2007; Environment Canada, 2007). In addition, many practitioners indicated that more refined, regional-scale climate-change scenarios are needed. Regional global climate models are not yet available for the Yukon, a lack which may be attributable to the poor climate monitoring network and the present limitations in the ability of global climate models to represent observational data from the Arctic, subArctic, and mountainous regions with accuracy (e.g., Walsh and Crane, 1992; Tao et al., 1996; Walsh et al., 2002; Bonsal et al., 2003; Chapman and Walsh, 2007). As this uncertainty is unlikely to be reduced in the near future, there is a need to identify forest management options and strategies that are likely to perform well across a range of future climate conditions (as suggested by Ogden and Innes, 2009).

\section{Community-Based Forest Monitoring Program}

Local observations are critical, as they may indicate areas that need further research and monitoring to understand cause and effect. The presence of local observations that have not been reported previously are a strong indication of the value of local residents, particularly those who spend time on the land, in providing an "early warning system" of unexpected changes and surprises. Both science and local knowledge systems can play a role in examining what may be the causal factors behind such observations. In addition, some observations may be of sufficient concern to local residents that they warrant closer attention by decision makers to developing management responses. These facts highlight the importance of formalizing a community monitoring network based on local knowledge as part of a broader adaptive management framework. Local monitoring can also empower local residents, who have an important role in setting forest management directions in the Yukon and across the Canadian North, to develop and advance their own interests in planning for adaptation and implementing adaptation plans.

Some scientists may express concerns that local observations (e.g., "new little green worms" or "new black vegetation") must be converted into scientific language to be relevant in an academic or management context. In the context of multiple knowledge systems, it should not be necessary, nor would it be appropriate in a community-directed resource management context, to validate local observations through science. However, the use of consistent terminology can aid communication by making observations more comparable between different observers and between the two knowledge systems.

\section{Improving Research Communication}

Local residents placed greater emphasis on the need for more communication and extension of research and monitoring results than did practitioners. Contrary to our expectations, few of the research needs suggested by the practitioners could be considered extension needs (e.g., where information already exists but is either not known or not accessible to forest practitioners). In another study (Ogden and Innes, 2007), practitioners in the Yukon and Northwest Territories indicated that they considered their knowledge of climate change to be poor. However, their identification of real research needs suggests that they may have underestimated their level of knowledge relative to what is available.

\section{CONCLUSIONS}

To help address the challenge of climate change through regional forest management, forest practitioners and local residents in the southwest Yukon identified a number of research and monitoring needs that would support adaptation decision making and the achievement of local forest management objectives. A better understanding of how climate change may affect the region's forests is needed. Strategies and practices that will help forest management policies and practices, forest ecosystems, and forest-based communities adapt to a changing climate need to be further explored. Monitoring to track indicators of change and to assess the effectiveness of management practices and policies in achieving management objectives needs to take place. Local residents highlighted the importance of formalizing a community-based monitoring network soundly based in local knowledge as part of a broader adaptive management framework. They also wanted to ensure that local residents play a major role in any deliberations about adapting existing management plans, practices, and policies to 
incorporate climate change considerations. Practitioners highlighted the importance of research and monitoring in the identification of forest management tactics and strategies that are suitable to help achieve community-directed forest management goals and objectives.

Addressing the research needs identified in this study will have benefits beyond the adaptation of forest management to climate change. In many ways, climate change is providing an impetus and a forum for discussion of the need for a more comprehensive research and monitoring program in the region than currently exists. Both this discussion and an improved research and monitoring program are prerequisites for the sustainable management of forest resources. A strategic approach is needed to address the extensive list of research and monitoring needs. In addition, any element of a decision-support research program should have local support. Local involvement in project planning needs to be effective to ensure that the results are meaningful locally. Subsequent work to prioritize the list of research needs generated by this study is needed. Efforts to enhance linkages between local observers and local knowledge, scientists and global scientific knowledge, and government decision-making processes present an opportunity to enhance adaptive capacity by building trust, developing interpersonal relationships, and increasing knowledge sharing, all of which are essential to successful adaptation.

This study has shown that efforts to identify the research required to support adaptation decision making will benefit from 1) participatory approaches that incorporate local, scientific, and government knowledge and expertise and 2) mainstreaming identification of research needs in the scale and context within which decisions are made. In this case, the scale was a forest management planning region and its associated strategic forest management plan. Research carried out at this scale will address the needs of local decision makers and support the development of policies to reduce risks and vulnerabilities associated with climate change. Over time, it will also contribute to the broader knowledge base on the effectiveness and appropriate application of alternative adaptation options.

\section{ACKNOWLEDGEMENTS}

The authors gratefully acknowledge the financial support for the practitioner sessions provided by the Social Sciences and Humanities Research Council under the Canada Graduate Scholarship program, the Model Forest Program, Champagne and Aishihik First Nations Government, the Government of Yukon, and the National Science Foundation's Climate Decision Making Centre. The sessions were facilitated by Dan Ohlson of Compass Resource Management. The project planning team consisted of Aynslie Ogden, John Innes, Dan Ohlson, Susan Skaalid, Roger Brown, Gary Miltenberger, and Tim McDaniels. Members of the local Research and Monitoring Technical Working Group provided invaluable feedback on the project proposal and the practitioner invitation list.
The community workshop entitled "Climate Change in our Backyard" was hosted by the Champagne and Aishihik First Nations and the Alsek Renewable Resource Council. The workshop was funded by Environment Canada's Northern Ecosystem Initiative, the Northern Climate ExChange, C-CIARN North, the Government of Yukon, the Council of Yukon First Nations, the Champagne and Aishihik First Nations, the Department of Indian and Northern Affairs, and the Aboriginal and Northern Community Action Program. The workshop was facilitated by Rose Kushniruk and Aynslie Ogden. The workshop planning team consisted of Rose Kushniruk, Fran Oles, Aynslie Ogden, Susan Desjardins, Michael Westlake, and Bob Van Dijken. Rose Kushniruk and Aynslie Ogden co-facilitated the workshop, and Amy McKinnon compiled the workshop report. Special acknowledgment goes to Rose Kushniruk, whose efforts made this workshop a resounding success. The authors also wish to thank the referees for their valuable suggestions during the preparation of this manuscript.

\section{REFERENCES}

ACIA (Arctic Climate Impact Assessment). 2004. Impacts of a warming Arctic: Arctic climate impact assessment. Cambridge: Cambridge University Press. 140 p.

ARRC (Alsek Renewable Resource Council). 2004. Strategic forest management plan for the Champagne and Aishihik Traditional Territory: Community directions for a sustainable forest. Whitehorse: Government of Yukon.

Berkes, F., and Jolly, D. 2002. Adapting to climate change: Socialecological resilience in a Canadian Western Arctic community. Conservation Ecology 5(2):18. [online] URL: http://www. consecol.org/vol5/iss2/art18/.

Bonsal, B.R., Prowse, T.D., and Pietroniro, A. 2003. An assessment of global climate model-simulated climate for the western cordillera of Canada (1961-90). Hydrological Processes 17(18):3703-3716.

C-CIARN North (Canadian Climate Impacts and Adaptation Research Network North). 2004a. Research needs survey literature review: Previously identified research needs. Whitehorse: Northern Climate Exchange, Yukon College.

- 2004b. Research needs survey: Online survey results. Whitehorse: Northern Climate Exchange, Yukon College.

_ 2004c. Research needs survey: Yukon community survey results. Whitehorse: Northern Climate Exchange, Yukon College.

CCIS (Canadian Climate Impacts and Scenarios). 2007. Bioclimateprofiles.http://www.cics.uvic.ca/scenarios/index. cgi?Bio-Climate_Profiles.

CFCAS (Canadian Foundation for Climate and Atmospheric Sciences). 2006. Overview. http://www.cfcas.org/overview_e. html.

Chapin, F.S., III, Hoel, M., Carpenter, S.R., Lubchenco, J., Walker, B., Callaghan, T.V., Folke, C., et al. 2006. Building resilience and adaptation to manage Arctic change. Ambio 35(4): 198-202. 
Chapman, W.L., and Walsh, J.E. 2007. Simulations of Arctic temperature and pressure by global coupled models. Journal of Climate 20(4):609-632.

Clark, J.S., Carpenter, S.R., Barber, M., Collins, S., Dobson, A., Foley, J.A., Lodge, D.M., et al. 2001. Ecological forecasts: An emerging imperative. Science 293(5530):657-660.

Clarke, D., and Slocombe, S. 2004. Re-negotiating science and protected areas: Lessons from grizzly bear conservation in the southwest Yukon, Canada. Proceedings of Presenting and Representing the Natural Environment: The Response of the Arts and Sciences - an Interdisciplinary Conference, 13-15 March 2004, Newtown, Wales. Canadian Studies in Wales Group, University of Wales.

Delong, C. 2004. A field guide to site identification and interpretation for the north central portion of the Northern Interior Forest Region. Land Management Handbook 54. Victoria, B.C.: British Columbia Ministry of Forests, Research Branch. http://www.for.gov.bc.ca/hfd/pubs/Docs/Lmh/Lmh54.htm.

Environment Canada. 2007. Canadian bioclimate profiles. http:// www.ccsn.ca/Help_and_Contact/Bioclimate_Profiles_Help-e. html.

Ford, J., Pearce, T., Smit, B., Wandel, J., Allurut, M., Shappa, K., Ittusujurat, H., and Qrunnut, K. 2006. Reducing vulnerability to climate change in the Arctic: The case of Nunavut, Canada. Arctic 60(2):150-166.

Gamborg, C.H., Parrotta, J.A., and Thorsen, B.J., eds. 2004. The forest science/policy interface: Building bridges to a sustainable future. Scandinavian Journal of Forest Research 19(Suppl. No. 4). 176 p.

Garbutt, R.W. 2005. Yukon 2005 forest health report. Victoria, British Columbia: Natural Resources Canada, Pacific Forestry Service and Whitehorse: Government of Yukon, Energy, Mines and Resources. http://www.emr.gov.yk.ca/forestry/foresthealth. html.

Garbutt, R.W., Hawkes, B.C., and Allen, E.A. 2007. Spruce beetle and the forests of the southwest Yukon. Victoria, British Columbia: Natural Resources Canada.

Gearheard, S., Matumeak, W., Angutikjuaq, I., Maslanik, J., Huntington, H.P., Leavitt, J., Matumeak Kagak, D., Tigullaraq, G., and Barry, R.G. 2006. It's not that simple: A collaborative comparison of sea ice environments, their uses, observed changes, and adaptations in Barrow, Alaska, USA, and Clyde River, Nunavut, Canada. Ambio 35(4):203-211.

IPCC (Intergovernmental Panel on Climate Change). 2007. Climate change 2007: Impacts, adaptation and vulnerability. Contribution of Working Group II to the Fourth Assessment Report of the IPCC. Cambridge: Cambridge University Press.

IPY (International Polar Year). 2005. Community consultation reports.http://www.ipy-api.ca/english/communications/ consultation.html.

IUFRO (International Union of Forest Research Organizations). 2007. Report on the training workshop, "Working Effectively at the Interface of Forest Science and Forest Policy" held at Muguga, Kenya, 4-6 December 2007, IUFRO Special Programme for Developing Countries. http://www.iufro.org/ science/special/spdc/actpro/wkspmal07/trainwshpnairobi/.
Juday, G.P., Barber, V., Duffy, P., Linderhorm, H., Rupp, S., Sparrow, S., Vaganov, E., and Yarie, J. 2005. Forests, land management and agriculture. In: Arctic climate impact assessment: Scientific report. Cambridge: Cambridge University Press. 781-862.

Kandlikar, M., Risbey, J., and Dessai, S. 2005. Representing and communicating deep uncertainty in climate-change assessments. Comptes Rendus Géosciences 337(4):443-455.

Keskitalo, E.C.H. 2004. A framework for multi-level stakeholder studies in response to global change. Local Environment 9(5):425-435.

Kloprogge, P., and Van der Sluijs, J.P. 2006. The inclusion of stakeholder knowledge and perspectives in integrated assessment of climate change. Climatic Change 75:359-389.

Mallory, M.L., Ogilvie, C., and Gilchrist, H.G. 2006. A review of the Northern Ecosystem Initiative in Arctic Canada: Facilitating Arctic ecosystem research through traditional and novel approaches. Environmental Monitoring and Assessment 113:19-29.

McKinnon, A. 2006. Climate change in our backyard. In: Proceedings from Workshop in Haines Junction, Yukon, 31 March - 2 April 2006. Haines Junction: Champagne and Aishihik First Nations (CAFN) and Alsek Renewable Resource Council (ARRC), Yukon. Available from CAFN, Department of Heritage, Lands and Resources, Box 5310, Haines Junction, Yukon YOB 1L0 or ARRC, 2077, Haines Junction, Yukon YOB 1LO.

Morgan, M.G., and Keith, D.W. 1995. Subjective judgments by climate experts. Environmental Science and Technology 29(10):468-476.

Morgan, M.G., Pitelka, L.F., and Shevliakova, E. 2001. Elicitation of expert judgments of climate change impacts on forest ecosystems. Climatic Change 49:279-307.

Moss, R.H., and Schneider, S.H. 2000. Uncertainties in the IPCC TAR: Recommendations to lead authors for more consistent assessment and reporting. In: Pachauri, R., Taniguchi, T., and Tanaka, K., eds. Guidance papers on the cross cutting issues of the Third Assessment Report of the IPCC. Geneva, Switzerland: World Meteorological Organization. 33-51.

Newton, J., Paci, C.D., and Ogden, A. 2005. Climate change and natural hazards in northern Canada: Integrating indigenous perspectives with government policy. Mitigation and Adaptation Strategies for Global Change 10:541-571.

NSERC (Natural Sciences and Engineering Research Council of Canada). 2004. Dialogue on northern research: Summary report. Ottawa, Ontario. http://www.cihr-irsc.gc.ca/e/25228. html.

. 2007. Northern Research Report 2006-07. Ottawa: NSERC.

Ogden, A.E. 2007. Forest management in a changing climate: Building the environmental information base for the southwest Yukon. Forestry Chronicle 83(6):806-809.

Ogden, A.E., and Innes, J.L. 2007. Perspectives of forest practitioners on climate change adaptation in the Yukon and Northwest Territories of Canada. Forestry Chronicle 83(4): 557-569.

. 2009. Application of structured decision making to an assessment of climate change vulnerabilities and adaptation 
options for sustainable forest management. Ecology and Society 14(1)11. [online] URL: http://ecologyandsociety.org/ vol14/iss1/art11/.

Parks Canada. 2000. Report of the Panel on the Ecological Integrity of Canada's National Parks, 2 vols. http://www.pc.gc. ca/docs/pc/rpts/ie-ei/report-rapport_1_E.asp.

Reidlinger, D., and Berkes, F. 2001. Contributions of traditional knowledge to understanding climate change in the Canadian Arctic. Polar Record 37(203):315 - 328.

RMTWG (Research and Monitoring Technical Working Group). 2005. Preliminary research and monitoring plan to support the implementation of the strategic forest management plan for the Champagne and Aishihik traditional territory: A focus on fundamentals. Whitehorse: Champagne and Aishihik First Nations and Government of Yukon. Available from the Department of Energy, Mines and Resources, Government of Yukon, Box 2703, Whitehorse, Yukon Y1A 2C6.

Schneider, S.H. 2003. The case for climate change action. Presentation to the U.S. Senate Committee on Commerce, Science and Transportation Hearing on October 1, 2003. Stanford, California: Center for Environmental Science and Policy, Stanford University.

SSHRC (Social Sciences and Humanities Research Council of Canada). 2007. Northern research at the forefront for SSHRC. Press Release, 17 April 2007. http://www.sshrc-crsh.gc.ca/site/ whatsnew-quoi_neuf/pr-communiques/2007/northern-nordeng.aspx.
Tao, X., Walsh, J.E., and Chapman, W.L. 1996. An assessment of global climate model simulations of Arctic air temperatures. Journal of Climate 9(5):1060-1076.

Timko, J., and Innes, J.L. 2009. Evaluating ecological integrity in National Parks: Case studies from Canada and South Africa. Biological Conservation 142(3):676-688, doi:10.1016/j. biocon.2008.11.022.

Walsh, J.E., and Crane, R.G. 1992. A comparison of GCM simulations of Arctic climate. Geophysical Research Letters (19)1:29-32.

Walsh, J.E., Kattsov, V.M., Chapman, W.L., Govorkova, V., and Pavlova, T. 2002. Comparison of Arctic climate simulations by uncoupled and coupled global models. Journal of Climate 15(12):1429-1446.

Williamson, T.B., Parkins, J.R., and McFarlane, B.L. 2005. Perceptions of climate change risk to forest ecosystems and forest-based communities. Forestry Chronicle 81(5):710-716.

Williamson, T.B., Price, D.T., Beverly, J.L., Bothwell, P.M., Parkins, J.R., Patriquin, M.N., Pearce, C.B., Stedman, R.C., and Volney, W.J.A. 2007. A framework for assessing vulnerability of forestbased communities to climate change. Information Report NOR-X-414. Edmonton: Northern Forestry Centre, Canadian Forest Service, Natural Resources Canada. 40 p.

Wortley, D. 2003. Community-based forest management planning in the Yukon: The difficulties of government transfer of responsibility and authority to community agencies. MSc thesis, Department of Renewable Resources, University of Alberta. 